\title{
Improving the Performance of a Semitransparent BIPV by Using High-Reflectivity Heat Insulation Film
}

\author{
Huei-Mei Liu, ${ }^{1}$ Chin-Huai Young, ${ }^{2}$ Der-Juinn Horng, \\ Yih-Chearng Shiue, ${ }^{1}$ and Shin-Ku Lee ${ }^{3}$ \\ ${ }^{1}$ Department of Business Administration, National Central University, Taoyuan 320, Taiwan \\ ${ }^{2}$ Department of Construction Engineering, National Taiwan University of Science and Technology, Taipei 106, Taiwan \\ ${ }^{3}$ Research Center for Energy Technology and Strategy, National Cheng Kung University, Tainan 701, Taiwan \\ Correspondence should be addressed to Shin-Ku Lee; sklee1015@gmail.com
}

Received 24 February 2016; Revised 8 May 2016; Accepted 22 May 2016

Academic Editor: Prakash Basnyat

Copyright (C) 2016 Huei-Mei Liu et al. This is an open access article distributed under the Creative Commons Attribution License, which permits unrestricted use, distribution, and reproduction in any medium, provided the original work is properly cited.

\begin{abstract}
Currently, standard semitransparent photovoltaic (PV) modules can largely replace architectural glass installed in the windows, skylights, and facade of a building. Their main features are power generation and transparency, as well as possessing a heat insulating effect. Through heat insulation solar glass (HISG) encapsulation technology, this study improved the structure of a typical semitransparent PV module and explored the use of three types of high-reflectivity heat insulation films to form the HISG building-integrated photovoltaics (BIPV) systems. Subsequently, the authors analyzed the influence of HISG structures on the optical, thermal, and power generation performance of the original semitransparent PV module and the degree to which enhanced performance is possible. The experimental results indicated that the heat insulation performance and power generation of HISGs were both improved. Selecting an appropriate heat insulation film so that a larger amount of reflective solar radiation is absorbed by the back side of the HISG can yield greater enhancement of power generation. The numerical results conducted in this study also indicated that HISG BIPV system not only provides the passive energy needed for power loading in a building, but also decreases the energy consumption of the HVAC system in subtropical and temperate regions.
\end{abstract}

\section{Introduction}

Both soaring energy costs and the effects of climate change mean that greater attention is now being paid to reducing energy consumption. According to a report by the International Energy Agency (IEA) [1], to prevent a further rise in the global temperature of $2^{\circ} \mathrm{C}$ by 2050 , it is necessary to set annual reduction goals for greenhouse gas emissions, with reductions in energy use being an important part of this. The energy consumption of the construction sector accounts for around $30 \%$ to $40 \%$ of a country's total energy consumption and has the greatest potential for energy saving among all sectors. For example, it is estimated that emissions of carbon dioxide will be reduced by approximately 1.5 billion tons per year with the application of the design concepts of net zero energy or zero carbon buildings. As such, in recent years, many countries have been approving the planning, design, and construction of net zero energy buildings (or zero carbon buildings) and putting such buildings into their national policy objectives, thus further raising interest in this field [24].

Among all the available renewable energy sources, solar energy is the most abundant, being an inexhaustible source of clean energy. Moreover, photovoltaic (PV) module technology has been widely used in modern industry to directly convert solar energy into electricity. Traditionally, a PV module is installed in open areas that are exposed to direct sunlight in order to generate electricity. However, in an urban environment, there is limited space on a building's roof, and thus the walls or building curtains can be utilized effectively for this purpose. For instance, a PV module can be combined with construction components, such as glass curtains, walls, windows, or roof structures, to form an integrated design. This design is known as building-integrated photovoltaics 
(BIPV), and this technology shows great potential for the development of more effective solar modules. Theoretically, as a BIPV module is combined with building materials, it can effectively reduce overall construction costs and is thus expected to shorten the energy payback time (EPBT).

Researchers in many countries have been assessing the benefits of this technology. For example, in the United Kingdom, Hammond et al. [5] assessed a $2.1 \mathrm{~kW}_{\mathrm{p}}$ monocrystalline silicon BIPV module applied to a roof and found that its EPBT was 4.5 years. The results also showed that the implementation of a government program, the "Low Carbon Building Programme" (or LCBP), would facilitate the economic benefits of this BIPV module and further shorten the EPBT. In the United States, Keoleian and Lewis [6] assessed a $2 \mathrm{~kW}_{\mathrm{p}}$ thin-film-type $(\alpha$-Si) BIPV module integrated with a roof. They installed it in different regions from Portland, Oregon, to Phoenix, Arizona, to examine the EPBT, with the results showing that this lay between 3.39 and 5.52 years. Lu and Yang assessed a $22 \mathrm{~kW}_{\mathrm{p}}$ monocrystalline silicon BIPV module used on a roof and wall in Hong Kong. When the module was installed in different orientations on the wall, its EPBT ranged from 7.1 years (the best scenario) to 20.0 years (when the module was installed on a vertical wall facing west) [7]. In Malaysia, Seng et al. [8] assessed $1 \mathrm{~kW}_{\mathrm{p}}$ BIPV modules using different crystalline Si technologies, namely, monocrystalline, polycrystalline, and thin-film-type $\alpha$-Si, in which the EPBTs were, respectively, 3.2-4.4, 2.2-3.0, and 1.92.6 years. In Europe, Oliver and Jackson [9] integrated a polycrystalline silicon BIPV module into building walls and found that its EPBT was 5.5 years. All these works show that BIPV modules have been widely studied and that many countries are making efforts to reduce the overall cost of installation in order to effectively reduce the EPBT, as well as achieve mass production and universalization.

Compared to the nontransparent BIPV module, the semitransparent BIPV module with improved visible light transmission performance has attracted greater attention in recent years. When a semitransparent PV module is integrated into building curtains, efficient visible light transmission can reduce the energy consumption of indoor lighting. With an appropriate design, solar radiation can even be reflected in an indoor environment, reducing building cooling energy usage directly, and so effectively enhance the thermal and visual comfort of a building. To achieve visible light transmission, this type of PV module mostly uses thin-film solar panel technology.

Copper indium gallium selenide (CIGS), amorphous silicon (a-Si), CdTe, and organic solar cells are widely used on the market. Moreover, CIGS solar cells have been used in building-attached photovoltaics (BAPV) [10]. However, the manufacturing costs of CIGS solar cells are still relatively higher, resulting in a greater EPBT. Therefore, recent studies tend to focus on a-Si thin-film-type solar panels. The module efficiency of a-Si solar cell is currently around 10\% [11]. Due to the single-junction structure of such cells, they are unable to absorb the solar energy spectrum effectively and so have a relatively low photoelectric conversion efficiency. Therefore, modern solar cell research has introduced dual-junction solar cells working in tandem $(\mathrm{a}-\mathrm{Si} / \mu \mathrm{c}-\mathrm{Si})$, which can widen the range of the solar light absorption spectrum by modulating the energy gap through the structure of tandem-junction module, improving the sunlight-to-electrical-energy conversion efficiency. The efficiency has now reached around $12.3 \%$ of the energy of standard sunlight $\left(1000 \mathrm{~W} / \mathrm{m}^{2}\right)$ for the tandem-junction modules now available on the market [11]. Although tandem-junction (a-Si/ $\mu \mathrm{c}-\mathrm{Si}$ ) technology can increase the power generation efficiency of a module, its efficiency is still lower than that of crystalline silicon-type and CIGS solar cells. Nevertheless, the literature [6-9] shows that the EPBTs of amorphous BIPV modules were shorter than those of crystalline silicon BIPV modules, because the construction costs of the latter are still too high.

Therefore, some a-Si/ $\mu \mathrm{c}-\mathrm{Si}$ manufacturers have moved towards manufacturing BIPV modules in order to develop a semitransparent PV module that can replace architectural glass, so that the building possesses good views and aesthetics. In the United Kingdom, Yun et al. [12] theoretically analyzed vertical solar panel walls and then analyzed the effects that different proportions of transparent windows and solar panels had on the indoor comfort and visible light utilization. They reported that transparent windows covering around $50 \%$ to $60 \%$ of the entire wall would achieve the best energy-saving effects in a building. The literature thus suggests that using light transmission is essential to zero carbon building design.

In Japan, Wong et al. [13] applied a semitransparent PV module to the skylight of a building. Under optimal conditions, the semitransparent solar skylight allowed $50 \%$ radiation transmission and could contribute a maximum of $5.3 \%$ of indoor heating and cooling energy consumption, as compared to a roof design using only an opaque BIPV. In China, Li et al. [14] made a theoretical analysis of the application of semitransparent PV modules in offices. Their results also showed that their application not only could reduce energy usage for indoor lighting and air-conditioning equipment, but also had a surplus electricity output, which will be conducive to the development of net zero energy buildings. In Saudi Arabia, Radhi [15] conducted an analysis of semitransparent PV modules applied to the south and west walls of a building. The EPBTs lay between 12 and 13 years, so, in order to effectively develop PV modules, it is necessary to consider and design them as a whole.

In Brazil, Didoné and Wagner [16] simulated the energysaving performance of semitransparent thin-film PV modules located in two different climates, in Brazil and the German city of Frankfurt. Their results showed that, with proper control, a semitransparent thin-film window can not only save energy for indoor lighting and air conditioning, but also generate surplus electricity. In 2014, Ng and Mithraratne reviewed the development of semitransparent PV modules and studied six types of commercially obtainable thin-film PV modules applied to office buildings in Singapore. Their study used a life cycle assessment (LCA) method to explore the EPBTs, carbon emissions, and cost reductions. The LCA method can be used to facilitate the design of a building [17], and the results showed that the application of a semitransparent PV module is more in line with the concept of zero 
carbon building compared to the use of an opaque BIPV module. Many studies have analyzed the energy efficiency of semitransparent PV modules and attempted to reduce the EPBT, with increasing the power generation ability being the main factor in this.

In a previous study [18], our team combined a thin-filmtype semitransparent PV module with a high-reflectivity heat insulation film to develop a type of heat insulation solar glass (HISG) that simultaneously possesses power generation, heat insulation, and energy-saving functions. After sunlight passes through the semitransparent PV module, the remaining light source will be reflected by the high-reflectivity heat insulation film to the back side of the semitransparent PV module, so that the module can once again absorb the reflected light and have a higher power output. Moreover, because of the multilayered structure of the HISG, the solar heat passing through the HISG can gradually be isolated in each layer of the material. After the sunlight passes through the first layer (the semitransparent PV module), part of the energy is converted to electrical energy. For the remaining radiant heat, the high-reflectivity heat insulation film will effectively isolate the residual radiant heat and block the ultraviolet light by $100 \%$.

The structure of the dual air gaps can reduce the thermal transmittance ( $U$-value), effectively isolating the conducted heat of the glass, so that the heat cannot be conducted from the glass to the indoor environment, and hence it has very good insulation properties. In terms of saving energy during summer, since the shading coefficient of HISG is very low, the heat of solar radiation cannot easily enter the building, significantly reducing the startup frequency of the air-conditioning compressor and thus achieving reduced energy consumption for cooling. During winter, since the thermal transmittance of the HISG is very low, the glass has good isolation and insulation performance, so warm air can be kept inside the room and cannot easily be dissipated, achieving reduced energy consumption for heating. The functional principles of the HISG are described in Figure 1.

In this research, we adopt three different types of semitransparent PV module technologies and combine three different types of energy-saving films with high reflectance to encapsulate HISG BIPV systems. Subsequently, we explore the optical and thermal properties and overall power generation effects and use simulation software to calculate the power generation and energy-saving effects of each HISG as applied to actual buildings in Taiwan, with a subtropical climate, and in London, England, with a temperate climate.

\section{Methodology}

2.1. Preparation of Heat Insulation Solar Glass. The proposed HISGs are mainly composed of a thin-film-type semitransparent PV module, high-reflectivity heat insulation film, and rear glass. HISG constructed in this study is a three-layer glazing system. The first layer is a transparent PV module, on the back of which is a $0.4 \mathrm{~mm}$ thick layer of high-reflectivity heat insulation film between two layers of spacers. Rear glass is placed behind the second spacer layer, which forms an air gap on both sides of the high-reflectivity heat insulation film. Three types of semitransparent PV module, a tandem laser module, tandem transparent conducting oxide (TCO) module, and a-Si TCO module, were selected as the front layer of the HISG in this study. The cell structure of these modules is illustrated in Figures 2(a), 2(b), and 2(c). In order to study the effects of heat insulation films with different reflectance values on the gains in power generation, heat insulation, and energy-saving performance of the HISG, this study adopts three different types of Heat Mirror films with different reflectance values.

2.2. Tests of Optical and Thermal Properties. Based on ISO 9050 and ISO 10292 [19, 20], a UV/Vis/NIR spectrophotometer (Hitachi U4100), FTIR spectrometer (Thermo iS50), and thermal conductivity analyzer (TCi) are used to measure the optical properties and thermal performance of the nine types of HISGs. The optical properties include solar direct transmittance $(300 \sim 2500 \mathrm{~nm})$, solar direct reflectance (300 $2500 \mathrm{~nm})$, visible light transmittance $(380 \sim 780 \mathrm{~nm})$, visible light reflectance $(380 \sim 780 \mathrm{~nm})$, and ultraviolet light transmittance $(300 \sim 380 \mathrm{~nm})$. The thermal performance properties include the solar heat gain coefficient (SHGC), shading coefficient (SC), and thermal transmittance ( $U$-value). Since the HISGs used in this study are multilayer ones composed of two or more sheets of flat glass, individual measurements must be made of every component during the optical measurements. The related formulae in ISO 9050 were used to calculate the overall optical and thermal performances. The relevant formulae are as follows.

2.2.1. Visible Light Transmittance, $\tau_{V}$, and Reflectance, $\rho_{V}$, of Triple Glazing. The light transmittance, $\tau_{V}$, and reflectance, $\rho_{V}$, of each component are calculated using the following formulae:

$$
\begin{aligned}
\tau_{V}= & \frac{\sum_{380}^{780} D_{\lambda} \times V(\lambda) \times \tau(\lambda) \times \Delta \lambda}{\sum_{380}^{780} D_{\lambda} \times V(\lambda) \times \Delta \lambda} \\
\rho_{V} & =\frac{\sum_{380}^{780} D_{\lambda} \times V(\lambda) \times \rho(\lambda) \times \Delta \lambda}{\sum_{380}^{780} D_{\lambda} \times V(\lambda) \times \Delta \lambda},
\end{aligned}
$$

where $D_{\lambda}$ is the relative spectral distribution of illuminant D65 (see ISO/CIE 10526), $\tau(\lambda)$ is the spectral transmittance of glazing, $\rho(\lambda)$ is the spectral reflectance of glazing, $V(\lambda)$ is the spectral luminous efficiency for photopic vision defining the standard observer for photometry, and $\Delta \lambda$ is the wavelength interval.

In the case of multiple glazing, the spectral transmittance $\tau(\lambda)$ and reflectance $\rho(\lambda)$ will be obtained by calculation from the spectral characteristics of the individual components. For the spectral transmittance $\tau(\lambda)$ and reflectance $\rho(\lambda)$ as a function of the spectral characteristics of the individual components of the unit, the following formulae are obtained: 


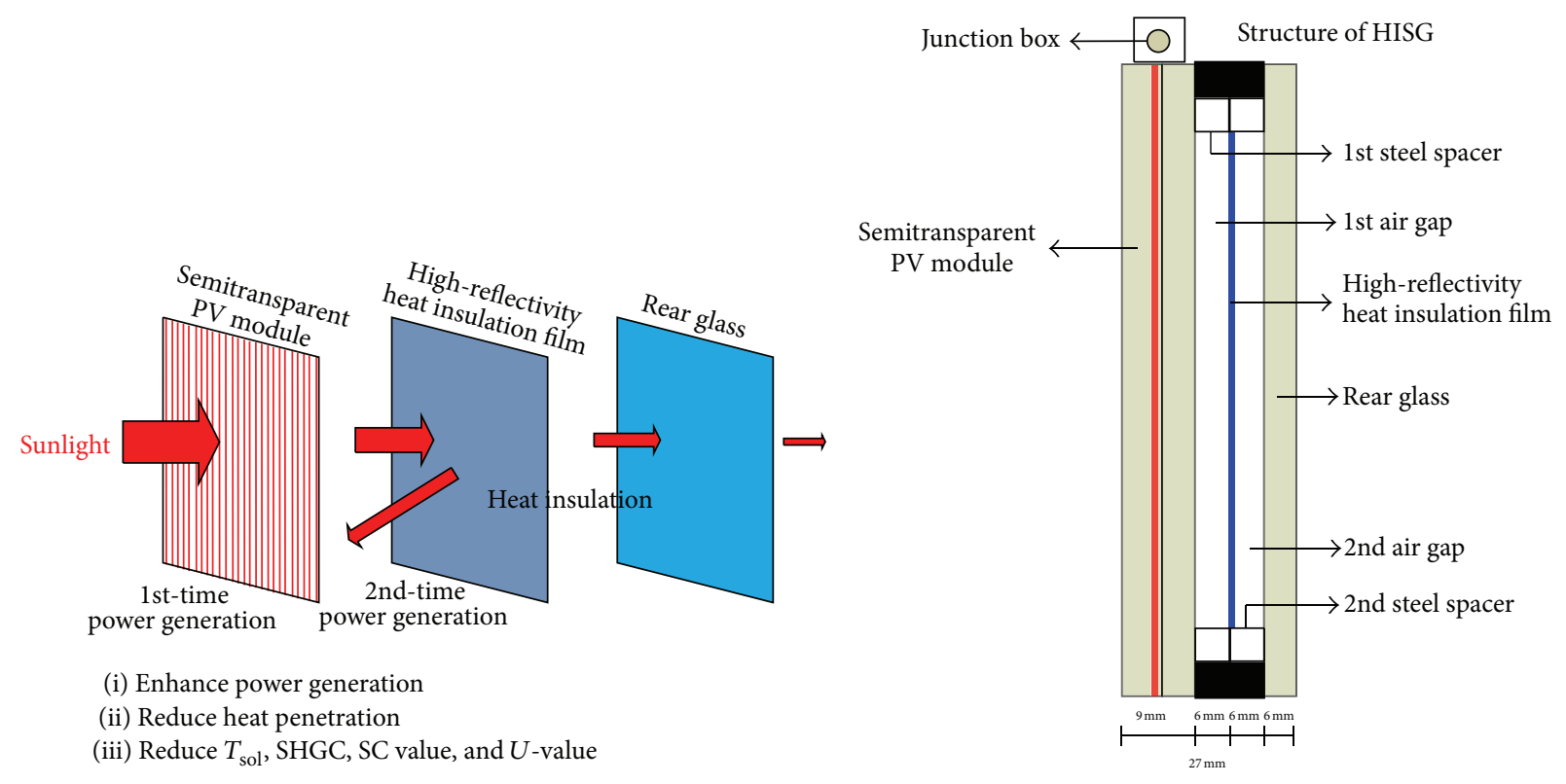

(a)

(b)

FIGURE 1: Functional principles and cross-sectional structure of heat insulation solar glass.

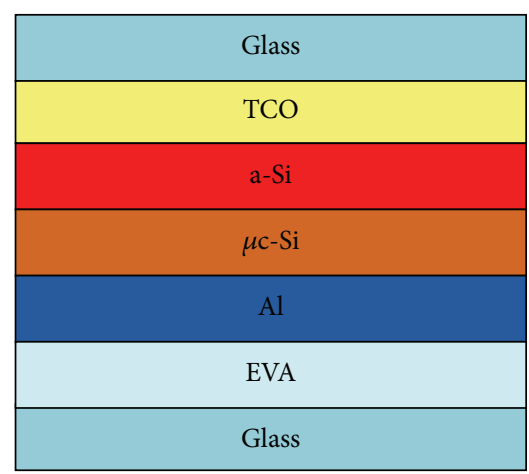

(a) Tandem laser module

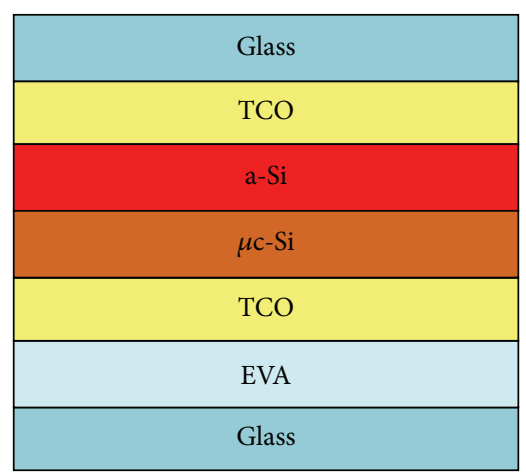

(b) Tandem TCO module

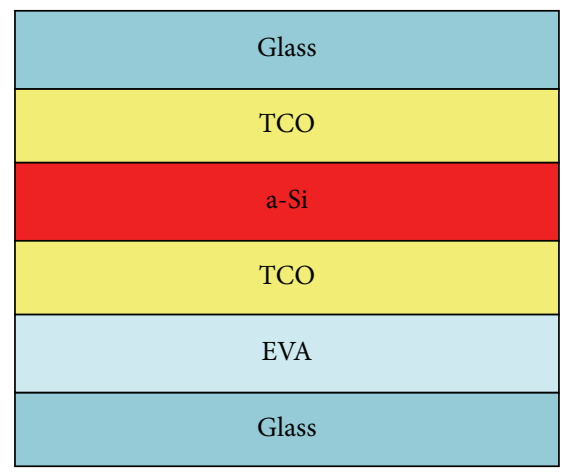

(c) a-Si TCO module

FIgURE 2: Cell structure of the tandem laser, tandem TCO, and a-Si TCO module.

$$
\begin{aligned}
& \tau(\lambda)=\frac{\tau_{1}(\lambda) \times \tau_{2}(\lambda) \times \tau_{3}(\lambda)}{\left[1-\rho_{2}(\lambda) \times \rho_{1}^{\prime}(\lambda)\right]\left[1-\rho_{3}(\lambda) \times \rho_{2}^{\prime}(\lambda)\right]-\tau_{2}^{2} \rho_{3}(\lambda) \times \rho_{1}^{\prime}(\lambda)} \\
& \rho(\lambda)=\rho_{1}(\lambda)+\frac{\tau_{1}^{2}(\lambda) \times \rho_{2}(\lambda)\left[1-\rho_{2}^{\prime}(\lambda) \times \rho_{3}(\lambda)\right]+\tau_{1}^{2}(\lambda) \times \tau_{2}^{2}(\lambda) \times \rho_{3}(\lambda)}{\left[1-\rho_{1}^{\prime}(\lambda) \times \rho_{2}(\lambda)\right]\left[1-\rho_{2}^{\prime}(\lambda) \times \rho_{3}(\lambda)\right]-\tau_{2}^{2} \times \rho_{1}^{\prime}(\lambda) \times \rho_{3}^{\prime}(\lambda)},
\end{aligned}
$$

where $\tau_{1}(\lambda)$ is the spectral transmittance of the outer (first) pane; $\tau_{2}(\lambda)$ is the spectral transmittance of the second pane; $\tau_{3}(\lambda)$ is the spectral transmittance of the third (inner) pane; $\rho_{1}(\lambda)$ is the spectral reflectance of the outer (first) pane measured in the direction of incident radiation; $\rho_{1}^{\prime}(\lambda)$ is the spectral reflectance of the outer (first) pane measured in the opposite direction of incident radiation; $\rho_{2}(\lambda)$ is the spectral reflectance of the second pane measured in the direction of incident radiation; $\rho_{2}^{\prime}(\lambda)$ is the spectral reflectance of the second pane measured in the opposite direction of incident radiation; $\rho_{3}(\lambda)$ is the spectral reflectance of the third (inner) pane measured in the direction of incident radiation; $\rho_{3}^{\prime}(\lambda)$ is 
the spectral reflectance of the third (inner) pane measured in the opposite direction of incident radiation.

2.2.2. Solar Direct Transmittance, $\tau_{e}$, and Reflectance, $\rho_{e}$, of Triple Glazing. The solar direct transmittance and reflectance are obtained as follows:

$$
\begin{aligned}
\tau_{e}= & \frac{\sum_{780}^{2500} S_{\lambda} \times \tau(\lambda) \times \Delta \lambda}{\sum_{780}^{2500} S_{\lambda} \times \Delta \lambda}, \\
\rho_{e}= & \frac{\sum_{780}^{2500} S_{\lambda} \times \rho(\lambda) \times \Delta \lambda}{\sum_{780}^{2500} S_{\lambda} \times \Delta \lambda},
\end{aligned}
$$

where $S_{\lambda}$ is the relative spectral distribution of the solar radiation.

2.2.3. UV Transmittance. UV transmittance is obtained as follows:

$$
\tau_{e}=\frac{\sum_{300}^{380} S_{\lambda} \times \tau(\lambda) \times \Delta \lambda}{\sum_{300}^{380} S_{\lambda} \times \Delta \lambda} .
$$

2.2.4. U-Value Calculation. The thermal transmittance of glazing, also known as the $U$-value, is the rate of heat transfer through one square meter of glazing divided by the difference between the ambient temperatures on each side. The method specified by ISO 10292 is based on a calculation from the following equation:

$$
\frac{1}{U}=\frac{1}{h_{t}}+\frac{1}{h_{e}}+\frac{1}{h_{i}},
$$

where $h_{i}$ is the interior heat transfer coefficient; $h_{e}$ is the exterior heat transfer coefficient; $h_{t}$ is the conductance of the multiple glazing unit.

2.2.5. Total Solar Energy Transmittance. The total solar energy transmittance (also known as solar heat gain coefficient) is the sum of the solar direct transmittance $\tau_{e}$ and the secondary heat transfer factor $q_{i}$ towards the inside:

$$
g=\tau_{e}+q_{i}
$$

The secondary heat transfer factor results from heat transfer by convection and longwave IR-radiation of that part of the incident solar radiation which has been absorbed by the glazing. The secondary heat transfer factor towards the inside of triple glazing is calculated using the following formula:

$$
=\frac{\left(\left(\alpha_{e 1}+\alpha_{e 2}+\alpha_{e 3}\right) / h_{e}+\left(\alpha_{e 2}+\alpha_{e 3}\right) / \Lambda_{12}+\alpha_{e 3} / \Lambda_{23}\right)}{1 / h_{i}+1 / h_{e}+1 / \Lambda_{12}+1 / \Lambda_{23}},
$$

where $\alpha_{e 1}$ is the solar direct absorptance of the outer (first) pane within the triple glazing; $\alpha_{e 2}$ is the solar direct absorptance of the second pane within the triple glazing; $\alpha_{e 3}$ is the solar direct absorptance of the third pane of the triple glazing; $\Lambda_{12}$ is the thermal conductance between the outer surface of the outer (first) pane and the center of the second pane; $\Lambda_{23}$ is the thermal conductance between the center of the second pane and the center of the third pane.
2.2.6. Shading Coefficient (SC). The shading coefficient of glass is a measure of the total amount of heat passing through the glazing compared with that through single clear glass. It is approximately equal to the SHGC divided by 0.87 .

2.3. Test of Gains in Power Generation Performance. Tests of the gain in power generation were made based on the standard test conditions (STC) in the test standard given by the International Electrotechnical Commission, IEC 61646 [21], for a thin-film PV module, in order to explore the power generation characteristics of the nine types of HISG described above. The effects of each combination of materials on the gain in power generation capacity of the semitransparent PV module were then analyzed and compared.

2.4. Assessment of Energy-Saving Performance. In this study, Autodesk Ecotect Analysis was adopted to conduct simulations of building power generation and energy by adopting the results of the power generation test, optical test, and thermal test as the material parameters and choosing Tainan in Taiwan and London in the United Kingdom as the simulated locations. The simulation was used to obtain the power generation capacity and energy consumption performance of the HISGs in real-world applications on buildings in subtropical and temperate regions.

2.4.1. Building Model. Ecotect was used in this study to model a single building. The building body consists of a roof and four walls to form an enclosed space, in order to facilitate the simulation of air-conditioning energy consumption. The main body of the building is facing south. The roof has a monopitched roof structure with an incline angle of $23.5^{\circ}$ and is composed of 10 pieces $\times 10$ pieces, giving a total of 100 pieces of PV modules with a size of approximately $14 \mathrm{~m} \times 11 \mathrm{~m}$. The overall dimensions of the building body are approximately $14 \mathrm{~m} \times 10 \mathrm{~m} \times 8.3 \mathrm{~m}$, as illustrated in Figure 3 .

2.4.2. Setting Parameters for the Simulation. In terms of the material parameters, the four surrounding walls are defined as being constructed of composite materials $(110 \mathrm{~mm}$ brick outside plus $75 \mathrm{~mm}$ timber frame, with $10 \mathrm{~mm}$ plasterboard inside) with a $U$-value of $1.77 \mathrm{~W} / \mathrm{mK}$, whereas values for the material parameters of each PV module come from the results of the power generation and optical and thermal tests in this paper. For the air-conditioning energy consumption, this study uses a mixed-mode air-conditioning system for cooling and heating. The usage time is 24 hours, the comfort temperature range is $20^{\circ} \mathrm{C}-26^{\circ} \mathrm{C}$, the startup temperature setting for a cold room is $26^{\circ} \mathrm{C}$, and the startup temperature setting for a warm room is $18^{\circ} \mathrm{C}$. The simulation of the airconditioning energy consumption was conducted for a whole year.

\section{Results and Discussion}

3.1. Optical Properties. The transmittance and reflectance coefficient versus wavelength of each component are shown in Figures 4 and 5, respectively. Table 1 shows the optical 
TABLE 1: Optical properties of each component and HISGs.

\begin{tabular}{|c|c|c|c|c|c|}
\hline \multirow[b]{2}{*}{ Module } & \multicolumn{4}{|c|}{ Item } & \multirow[b]{2}{*}{$\begin{array}{c}\text { UV } \\
\text { transmittance }\end{array}$} \\
\hline & $\begin{array}{c}\text { Solar direct } \\
\text { transmittance }\end{array}$ & $\begin{array}{l}\text { Solar direct } \\
\text { reflectance }\end{array}$ & $\begin{array}{l}\text { Visible light } \\
\text { transmittance }\end{array}$ & $\begin{array}{l}\text { Visible light } \\
\text { reflectance }\end{array}$ & \\
\hline Tandem laser module & 7.09 & 10.07 & 8.4 & 5.27 & 0.01 \\
\hline Tandem TCO module & 18.33 & 6.79 & 2.20 & 5.15 & 0.01 \\
\hline a-Si TCO module & 23.49 & 7.30 & 4.35 & 5.12 & 0.01 \\
\hline Heat insulation film A & 68.14 & 16.88 & 95.32 & 4.83 & 1.75 \\
\hline Heat insulation film B & 40.63 & 30.89 & 84.12 & 6.01 & 1.36 \\
\hline Heat insulation film C & 33.15 & 40.71 & 61.04 & 22.33 & 1.00 \\
\hline Rear glass & 81.15 & 5.04 & 88.85 & 5.66 & 62.39 \\
\hline Tandem laser-A HISG & 4.07 & 10.17 & 7.23 & 5.35 & 0 \\
\hline Tandem laser-B HISG & 2.5 & 10.24 & 6.39 & 5.35 & 0 \\
\hline Tandem laser-C HISG & 2.08 & 10.30 & 4.78 & 5.45 & 0 \\
\hline Tandem TCO-A HISG & 10.34 & 7.44 & 1.88 & 5.15 & 0 \\
\hline Tandem TCO-B HISG & 6.26 & 7.88 & 1.66 & 5.15 & 0 \\
\hline Tandem TCO-C HISG & 5.16 & 8.21 & 1.23 & 5.15 & 0 \\
\hline a-Si TCO-A HISG & 13.26 & 8.37 & 3.72 & 5.14 & 0 \\
\hline a-Si TCO-B HISG & 8.03 & 9.09 & 3.29 & 5.14 & 0 \\
\hline a-Si TCO-C HISG & 6.62 & 9.64 & 2.43 & 5.17 & 0 \\
\hline
\end{tabular}

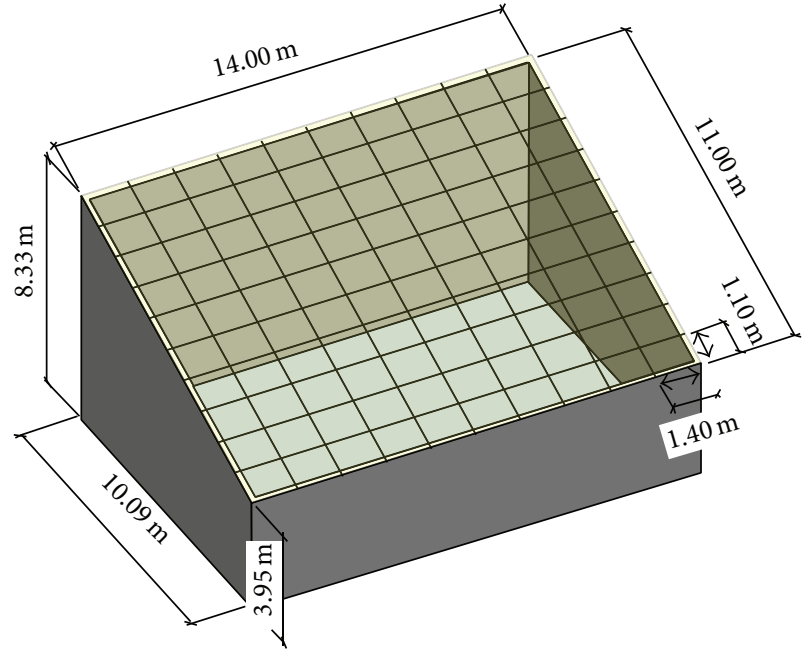

FIgURE 3: The 3D model of the building body.

properties of each component based on ISO 9050. The values of lighting transmittance for the three PV modules were in the 7.09-23.49 range, and those for the three heat insulation films were in the range of 33.15-68.14. The measurement results show that the tandem laser module and heat insulation film $C$ had better heat insulation effects. They could thus be used in hot climates, where there is a need to reduce solar heat transmission, especially in buildings where large transparent surfaces are fitted. Furthermore, the tandem laser module and heat insulation film $\mathrm{A}$ had better visibilities, even though with the former the back-contact electrode material is opaque. Part of the power-generating layers and back-contact electrode layer in the tandem laser module were removed using a transverse laser cutting method to enable the module to be light-transmissible. It is also worth noting that the lower visible light transmittance in other modules is mainly due to absorption of the TCO layers. The UV transmittances of the PV module and heat insulation film are less than $2 \%$, meaning that the performances of the HISGs with regard to isolating UV light were very good.

In the cell structure of the tandem TCO module, the materials of the power-generating layers are the same as those of the tandem laser module, but, in terms of the back-contact electrode, a TCO material with good light transmission and conduction properties was adopted. Though TCO has high optical transparency, it does decrease light transmission from UV to IR. Therefore, the tandem TCO module has a lighttransmissible property and its insulation of solar thermal energy is poorer than that of the tandem laser module. In addition, as the color of transmitted light tends to be wine red, part of its visible light transmittance was poorer. The material of the rear electrode in the cell structure of the a$\mathrm{Si}$ TCO module was the same as that of the tandem TCO module. As such, it also has a light-transmissible property and the transmitted light color tends to be orange red. However, in the power-generating layer, the a-Si TCO module had a single-layer structure without a layer of $\mu \mathrm{c}$-Si, so its visible light transmittance was slightly better than that of the tandem TCO module. Furthermore, as it has no $\mu \mathrm{c}$-Si layer to absorb the solar light, its solar radiation transmittance was slightly poorer than that of the tandem TCO module.

As shown in Figure 6, the measurement results for the solar direct transmittance indicated that the addition of a reflective layer reduces the transmittance of HISGs. For the tandem laser, tandem TCO, and a-Si TCO module, the solar direct transmittance was originally $7.09 \%, 18.33 \%$, 


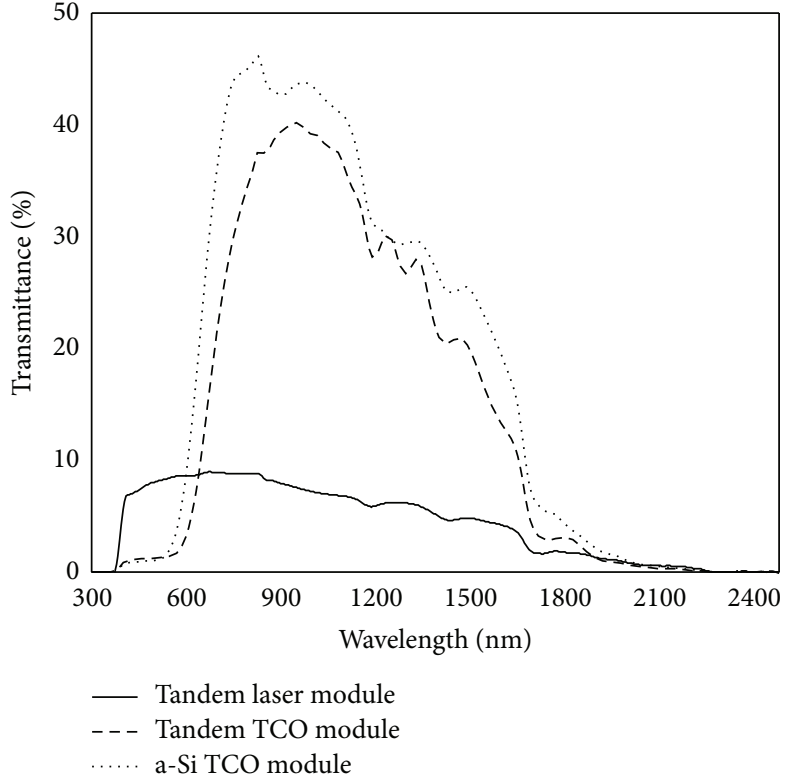

(a)

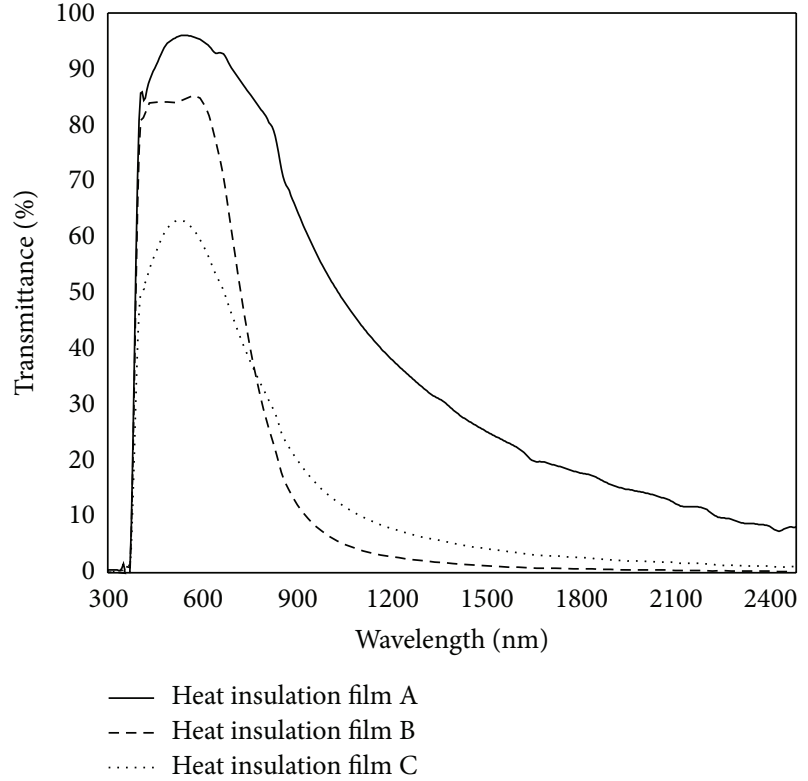

(b)

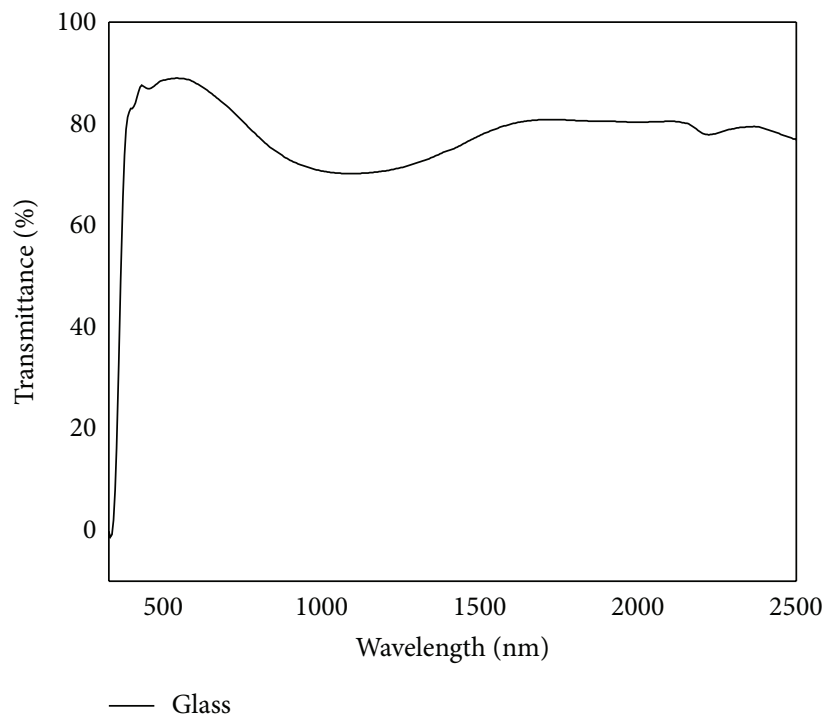

(c)

FIGURE 4: Transmittance spectra of each component: (a) semitransparent PV module, (b) heat insulation film, and (c) rear glass.

and $23.49 \%$, but after being encapsulated into the HISG it dropped to $2.08-4.07 \%, 5.16-10.34 \%$, and $6.62-13.26 \%$, respectively. The visible light transmittance was originally $8.4 \%, 2.2 \%$, and $4.35 \%$, but after being encapsulated into the HISG it dropped to $4.78-7.23 \%, 1.23-1.88 \%$, and $2.43-3.72 \%$, respectively.

After the various semitransparent PV modules were integrated into the HISG with the various heat insulation films, all their solar direct reflectance values increased slightly, so the encapsulation was slightly beneficial to the heat insulating effect of the HISGs. Moreover, after being encapsulated into the HISGs, the effects on the visible light reflectance were all less severe, falling to around 5\%. Therefore, the HISGs will not necessarily cause environmental light pollution.
With regard to the UV transmittance, since most of the UV light is absorbed by the semitransparent PV module and the heat insulation film, the UV transmittance values of all the HISGs are $0 \%$. This means that the UV isolation performances are very good and able to protect interior furnishings from aging and the skin from damage caused by UV radiation.

3.2. Thermal Properties. The surface emissivity of an object refers to its ability to release heat via thermal radiation after absorbing solar radiation. The surface emissivity of each component is thus an important parameter affecting the heat insulation performance of a HISG. In this paper, the spectral reflectance of each component on the exterior and interior 


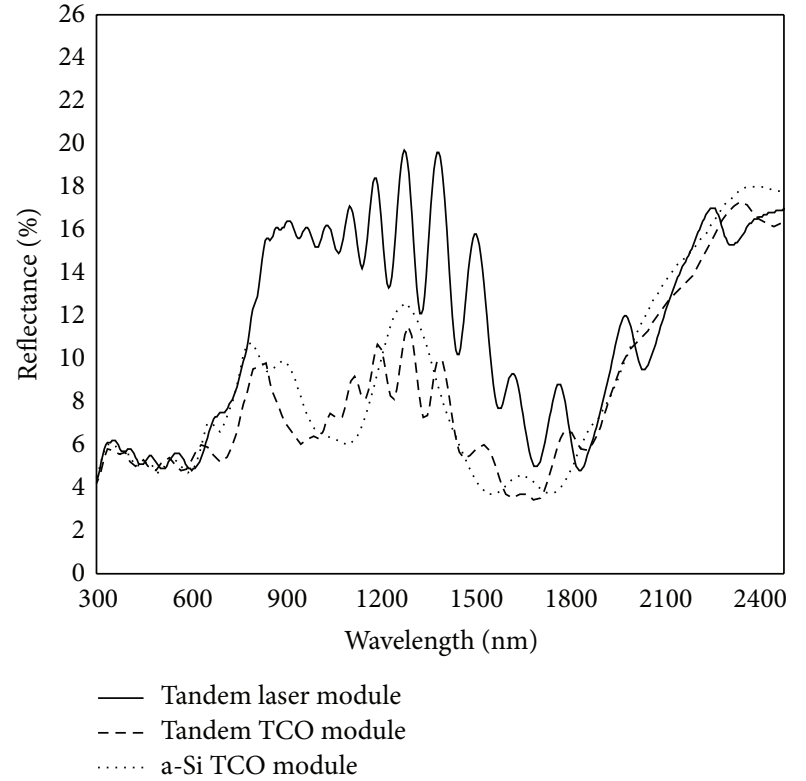

(a)

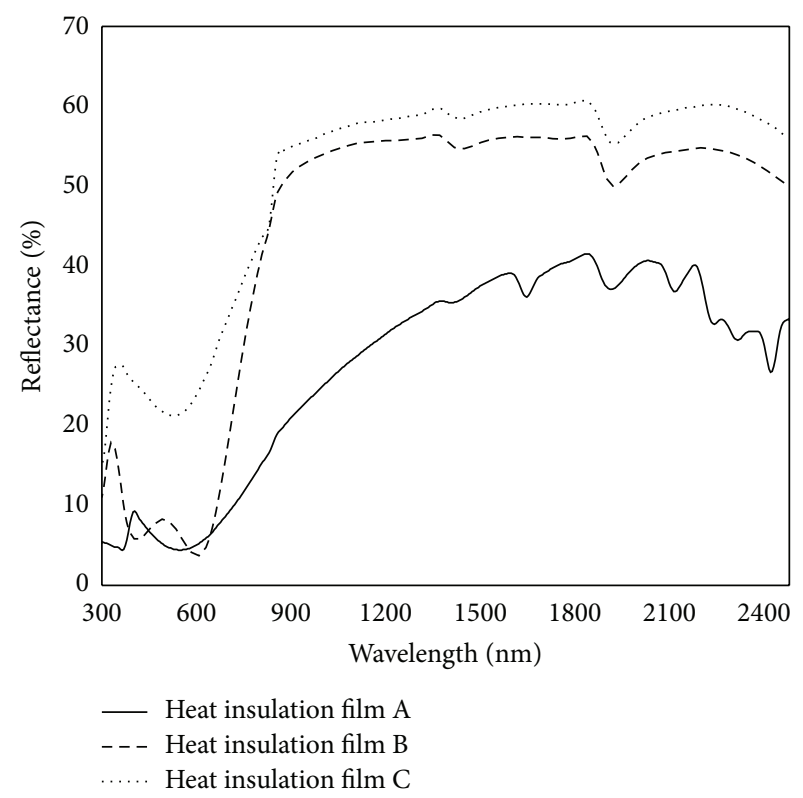

(b)

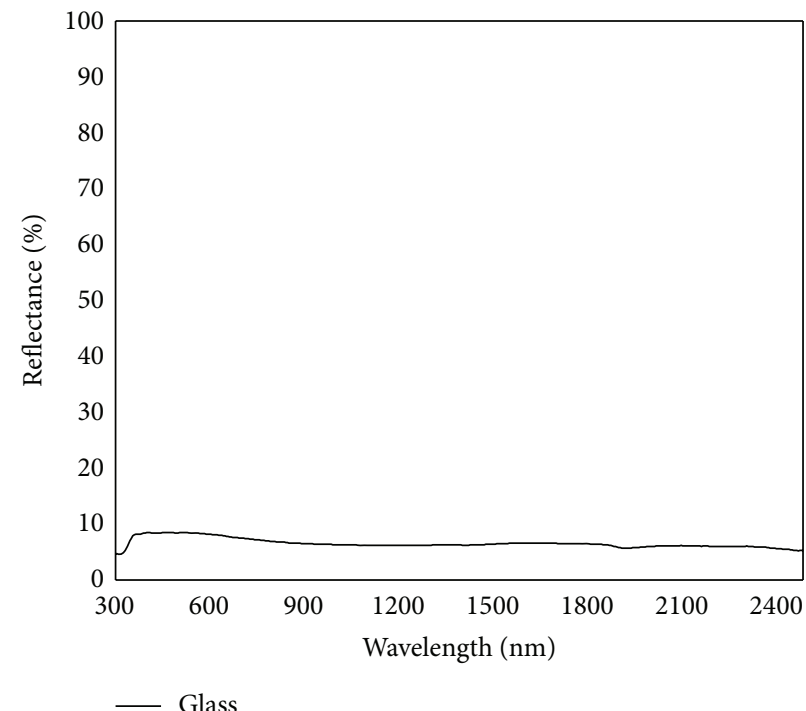

(c)

FIGURE 5: Reflectance spectra of each component: (a) semitransparent PV modules, (b) heat insulation films, and (c) rear glass.

sides was measured using FTIR, and then the emissivity value of each component was obtained by ISO 10292, as shown in Table 2. It can be seen that as the surfaces of the semitransparent PV modules and rear glass were not all coated by a film, the emissivity values for the exterior and interior sides were 0.84 . While the heat insulation films were mainly composed of PET material, there was no film coating the interior surface of the film, so the emissivity values were all 0.76. Meanwhile, the exterior surfaces of the heat insulation films all had a multilayer metal coating, so the surface emissivity values were lower than the surface emissivity values on the indoor side. The surface emissivity of heat insulation film $\mathrm{C}$ is 0.033 , which is thus categorized as a Low-E film.

Table 3 shows the thermal performances of the three types of PV modules and the nine types of HISGs, with the SHGCs, shading coefficients, and overall heat transfer coefficients $(U$ values). The results indicate that the multilayer structure of the HISG reduced the solar direct transmittance, and since the heat insulation films were coated with transparent metal films this reflected the solar radiation heat, prompting the SHGCs to be reduced to half the levels seen with the semitransparent PV modules. This means that the quantity of solar radiation heat passing through the HISG was half that 


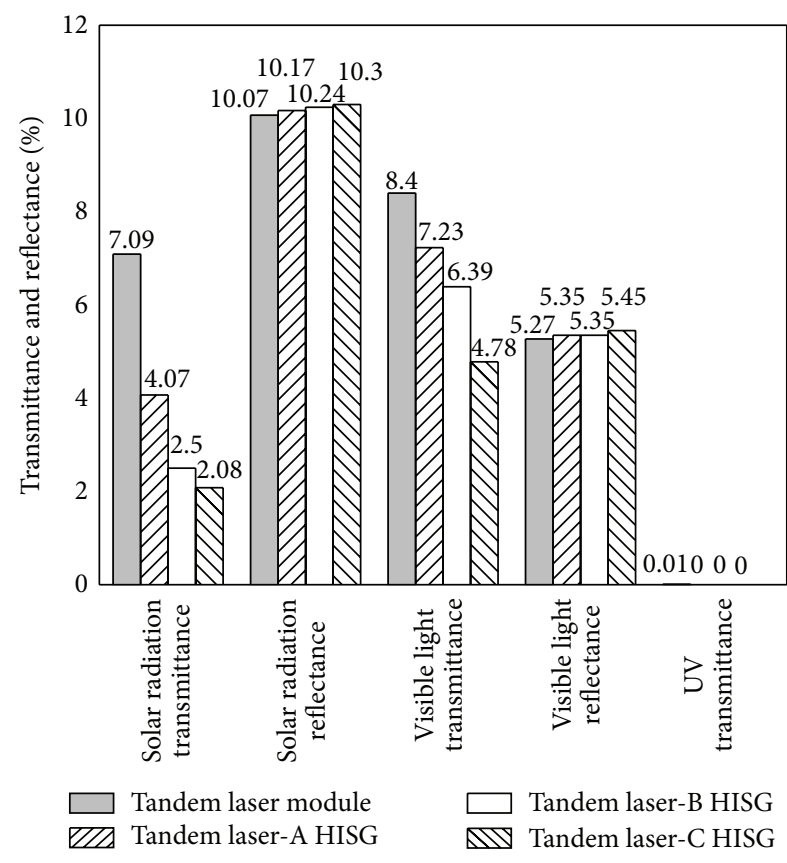

(a)

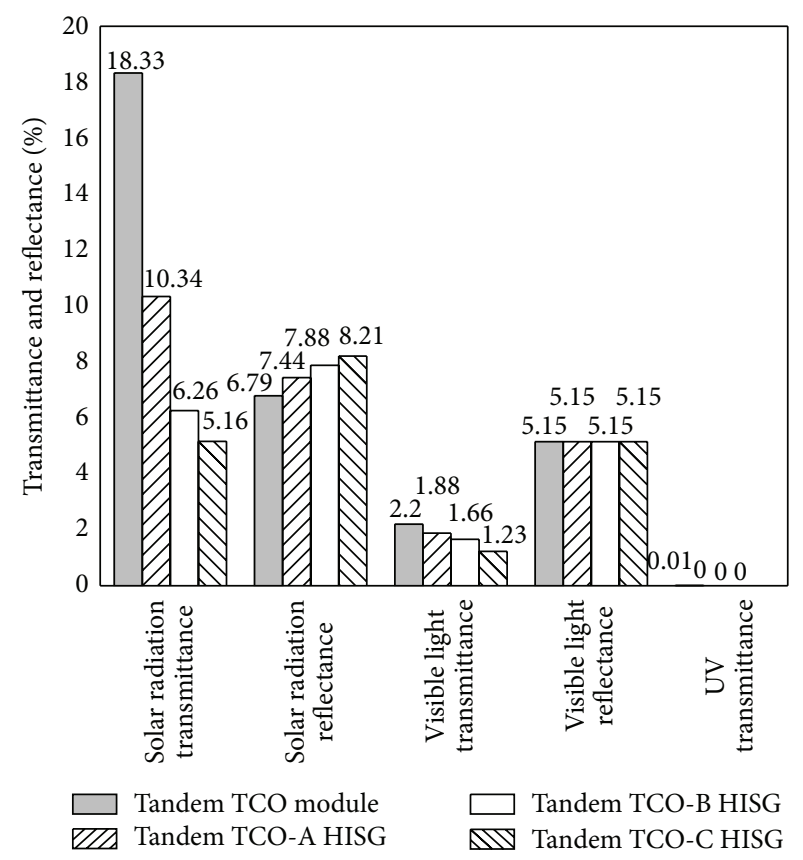

(b)

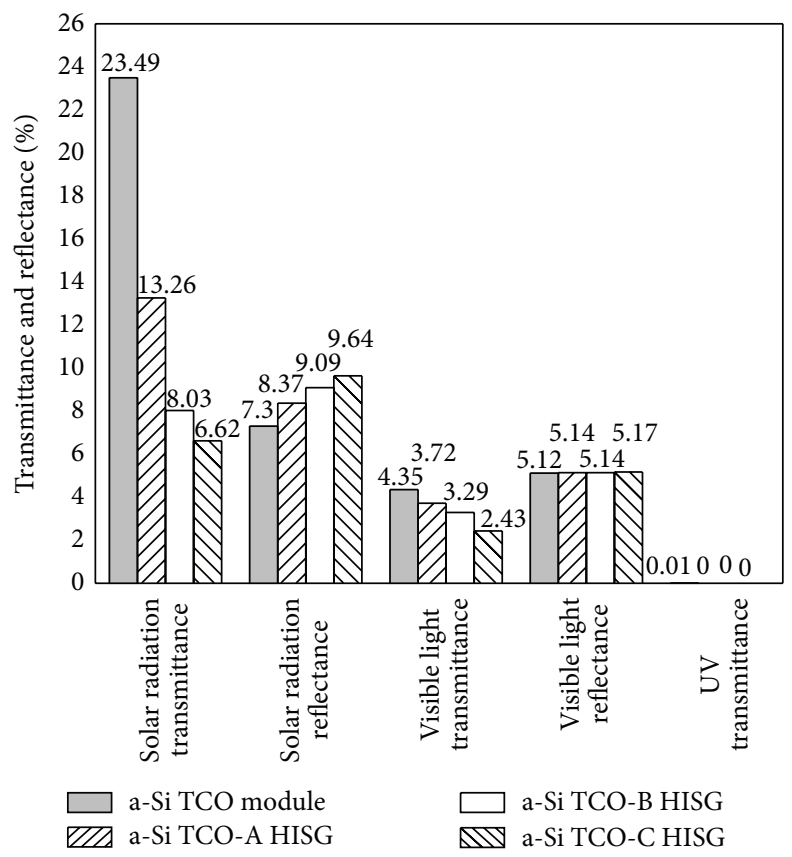

(c)

FIgURE 6: Optical properties of the HISGs: (a) tandem laser module, (b) tandem TCO module, and (c) a-Si TCO module.

passing through the semitransparent PV modules. In terms of the $U$-value, since all the semitransparent PV modules were assembled with $4 \mathrm{~mm} \times 4 \mathrm{~mm}$ laminated glass, the $U$ values based on ISO 10292 for all modules were $5.63 \mathrm{~W} / \mathrm{m}^{2}$ $\mathrm{K}$. The addition of heat insulation films and dual air gaps to form a multilayer structure greatly reduced the $U$-values of the HISGs $\left(1.755 \mathrm{~W} / \mathrm{m}^{2}-\mathrm{K}-1.824 \mathrm{~W} / \mathrm{m}^{2}-\mathrm{K}\right)$. Moreover, having heat insulation films with different emissivity values is one of the main causes of the decline in the $U$-value. Since heat insulation film $\mathrm{C}$ had the lowest surface emissivity, the HISGs assembled using film $\mathrm{C}$ also possessed lower $U$-values $\left(1.755 \mathrm{~W} / \mathrm{m}^{2}-\mathrm{K}\right)$.

3.3. Power Generation Gain Performance. The power generation test results for the front and back sides of each semitransparent PV module are shown in Table 4 . The measurement 
TABLE 2: Emissivity of each component.

\begin{tabular}{lcc}
\hline Item & $\begin{array}{c}\text { Emissivity of } \\
\text { indoor side }\end{array}$ & $\begin{array}{c}\text { Emissivity of } \\
\text { outdoor side }\end{array}$ \\
\hline Tandem laser module & 0.84 & 0.84 \\
Tandem TCO module & 0.84 & 0.84 \\
a-Si TCO module & 0.84 & 0.84 \\
\hline Heat insulation film A & 0.76 & 0.135 \\
Heat insulation film B & 0.76 & 0.045 \\
Heat insulation film C & 0.76 & 0.033 \\
\hline Rear glass & 0.84 & 0.84 \\
\hline
\end{tabular}

TABLE 3: Thermal properties of the semitransparent PV modules and HISGs.

\begin{tabular}{|c|c|c|c|}
\hline \multirow[b]{2}{*}{ Module } & \multicolumn{3}{|c|}{ Item } \\
\hline & SHGC & $\begin{array}{l}\text { Shading } \\
\text { coefficient }\end{array}$ & $U$-value \\
\hline $\begin{array}{l}\text { Tandem laser } \\
\text { module }\end{array}$ & 0.3 & 0.345 & 5.63 \\
\hline $\begin{array}{l}\text { Tandem laser-A } \\
\text { HISG }\end{array}$ & 0.151 & 0.174 & 1.824 \\
\hline $\begin{array}{l}\text { Tandem laser-B } \\
\text { HISG }\end{array}$ & 0.135 & 0.155 & 1.757 \\
\hline $\begin{array}{l}\text { Tandem laser-C } \\
\text { HISG }\end{array}$ & 0.129 & 0.148 & 1.755 \\
\hline $\begin{array}{l}\text { Tandem TCO } \\
\text { module }\end{array}$ & 0.38 & 0.437 & 5.63 \\
\hline $\begin{array}{l}\text { Tandem TCO-A } \\
\text { HISG }\end{array}$ & 0.218 & 0.25 & 1.824 \\
\hline $\begin{array}{l}\text { Tandem TCO-B } \\
\text { HISG }\end{array}$ & 0.184 & 0.211 & 1.757 \\
\hline $\begin{array}{l}\text { Tandem TCO-C } \\
\text { HISG }\end{array}$ & 0.171 & 0.196 & 1.755 \\
\hline $\begin{array}{l}\text { a-Si TCO } \\
\text { module }\end{array}$ & 0.41 & 0.471 & 5.63 \\
\hline $\begin{array}{l}\text { a-Si TCO-A } \\
\text { HISG }\end{array}$ & 0.249 & 0.286 & 1.824 \\
\hline $\begin{array}{l}\text { a-Si TCO-B } \\
\text { HISG }\end{array}$ & 0.207 & 0.238 & 1.757 \\
\hline $\begin{array}{l}\text { a-Si TCO-C } \\
\text { HISG }\end{array}$ & 0.19 & 0.218 & 1.755 \\
\hline
\end{tabular}

results show that the power output for the front side of the tandem laser module was $126.029 \mathrm{~W}$, with an efficiency of $8.184 \%$, while that of the back side was only $1.019 \mathrm{~W}$. The reason for this is the cell structure of the tandem laser module, as the bottom back-contact conductive layer is $\mathrm{Al}$, which does not possess power generation characteristics. Therefore, after being illuminated by direct light, there should not be a power generation effect. However, because the tandem laser module was subjected to transverse laser cutting during the manufacturing process, light can pass through from the back side. The light could then undergo refraction or transmission at the rear glass, so some of the light is able to enter the powergenerating layer from the laser cut slits, and so the back side
TABLE 4: Results of tests of electrical characteristics in STC for initial states of the original transparent PV module: (a) front side and (b) back side.

(a)

\begin{tabular}{lccc}
\hline Test item & $\begin{array}{c}\text { Tandem } \\
\text { laser } \\
\text { module }\end{array}$ & $\begin{array}{c}\text { Tandem } \\
\text { TCO } \\
\text { module }\end{array}$ & $\begin{array}{c}\text { a-Si } \\
\text { TCO } \\
\text { module }\end{array}$ \\
\hline $\begin{array}{l}\text { Module efficiency (\%) } \\
\text { Maximum power output }\end{array}$ & 8.184 & 8.11 & 7.78 \\
(W) & 126.029 & 124.843 & 119.796 \\
Open circuit voltage (V) & 167.382 & 171.629 & 111.606 \\
$\begin{array}{l}\text { Short circuit current (A) } \\
\text { Maximum voltage (V) }\end{array}$ & 1.133 & 1.038 & 1.595 \\
$\begin{array}{l}\text { Maximum electric current } \\
\text { (A) }\end{array}$ & 0.962 & 0.888 & 1.378 \\
Fill factor & 0.6644 & 0.7008 & 0.6731 \\
\hline
\end{tabular}

(b)

\begin{tabular}{lccc}
\hline Test item & $\begin{array}{c}\text { Tandem } \\
\text { laser } \\
\text { module }\end{array}$ & $\begin{array}{c}\text { Tandem } \\
\text { TCO } \\
\text { module }\end{array}$ & $\begin{array}{c}\text { a-Si } \\
\text { TCO } \\
\text { module }\end{array}$ \\
\hline $\begin{array}{l}\text { Module efficiency (\%) } \\
\text { Maximum power output }\end{array}$ & 0.066 & 0.723 & 5.361 \\
(W) & 1.019 & 11.134 & 82.566 \\
$\begin{array}{l}\text { Open circuit voltage (V) } \\
\text { Short circuit current (A) }\end{array}$ & 109.965 & 156.555 & 108.648 \\
$\begin{array}{l}\text { Maximum voltage (V) } \\
\text { Maximum electric current }\end{array}$ & 0.026 & 0.108 & 1.213 \\
(A) & 0.025 & 0.084 & 0.984 \\
Fill factor & 0.3506 & 0.6576 & 0.6264 \\
\hline
\end{tabular}

of the tandem laser module also possesses a slight power generation effect.

The power output of the front side of the tandem TCO module was $124.843 \mathrm{~W}$, with an efficiency of $8.11 \%$, whereas that of the back side was only $11.134 \mathrm{~W}$. The reason why the efficiency from back-side illumination is low is due to light absorption in the lower bandgap $\mu \mathrm{c}$-Si cell, which allows limited light into the a-Si cell. The current output would be limited by the smaller current value from the a-Si, and so a lower efficiency is generated.

The front-side power output of the a-Si TCO module was $119.796 \mathrm{~W}$, with an efficiency of $7.78 \%$, whereas the back-side power output of the a-Si TCO module reached $82.566 \mathrm{~W}$. The power-generating layer of the a-Si TCO module is the a-Si layer, which is also classified as a cell structure with dual-surface power generation characteristics, so the backside power output was higher compared to that of the former two modules. However, the reason for the difference in the front-side and back-side power outputs of the a-Si TCO module is that the materials of the front and rear glass were different. The front glass was ultraclear glass with more than $90 \%$ visible light transmittance. Meanwhile, in order to increase the loading strength of the BIPV, the rear glass was mostly tempered glass or heat-strengthened glass with 
lower transmissivity. In addition, before entering the powergenerating layer from the back side, the light still needs to pass through a layer of EVA plastic film, which will also reduce the solar irradiance. The back-side power output of the a-Si TCO module was thus only $69 \%$ of the front-side power output.

The results of the electrical tests of each semitransparent PV module and each combination of HISGs are shown in Table 5. The results for power generation gain are shown in Table 6. The experimental results indicated that both the power generation and efficiency of tandem laser HISG exhibited slightly increasing trends; the power generation increased by around $0.01-0.13 \%$ and the efficiency increased by around $0.001-0.01 \%$. However, the power generation and efficiency of tandem TCO HISG and a-Si TCO HISG displayed increasing trends. For the tandem TCO HISG, the power generation improved by around $3.27-10.06 \%$, and the efficiency increased by around $0.27-0.82 \%$. For the a-Si TCO HISG, the power generation increased by around $0.94-$ $3.07 \%$, and the efficiency increased by around $0.07-0.24 \%$. The power-generating layer of the tandem TCO module is a$\mathrm{Si} / \mu \mathrm{c}-\mathrm{Si}$, but that of the a-Si TCO module is a single layer of a-Si. The absorption spectrum of the tandem TCO module $(300 \mathrm{~nm}-1100 \mathrm{~nm})$ is wider than that of the a-Si TCO module $(300 \mathrm{~nm}-750 \mathrm{~nm})$. The back side of the tandem TCO HISG can thus absorb higher effective irradiance than the a-Si TCO HISG. This means that the efficiency enhanced rate of the tandem TCO HISG is higher than that of the a-Si TCO HISG. It is also worth noting that selecting an appropriate heat insulation film in order to absorb a larger amount of reflective solar radiation by the back side of the HISG can lead to greater enhancement of power generation.

3.4. Simulation of Energy-Saving Performance. The simulation results for the power generation of each HISG installed in the buildings and the energy consumption of the heating, ventilation, and air-conditioning (HVAC) system are shown in Table 7. As Tainan is located in a subtropical region in Taiwan, where there is sufficient sunlight, the annual power generation of each module was higher than that of the modules in London, and the power outputs ranged between $16,328 \mathrm{~kW}$ and $18,727 \mathrm{~kW}$. London is located in a temperate zone with mostly cloudy weather, and thus the annual power generation only ranged between $8493 \mathrm{~kW}$ and $9741 \mathrm{~kW}$. These results show that different climate zones and weather patterns are the main factors affecting the power generation of BIPV modules.

The simulation results in Table 7 also show that the power outputs of each HISG were larger than those of the original semitransparent PV modules. That is, the power enhancements of the tandem laser HISG were around $0.01-0.12 \%$, those of the tandem TCO HISG were around 3.27-10.06\%, and those of the a-Si TCO HISG were around $0.94-3.07 \%$. The simulated results also reveal that the percentage gains in power generation for each HISG installed on the roofs of buildings as BIPV roofs are consistent with the experimental results under STC from IEC 61646. Therefore, adding heat insulation films onto semitransparent PV modules to form a HISG in order to enhance the power output of the modules is beneficial in reducing the EPBT of the entire BIPV system.
The simulation results for the energy consumption of the HVAC systems of buildings in Tainan, Taiwan, and London, UK, are shown in Tables 8 and 9, respectively. As Tainan is located in a subtropical region, the use of a heater is less common and the HVAC system is mostly used for cooling, so the energy consumption for the latter is much higher than that for heating. On the other hand, London is located in a temperate region, and the HVAC system is mainly used for heating, so the energy consumption for this is much higher than that for cooling.

Furthermore, the main factors affecting the energy consumption of the HVAC system are the shading coefficient and the $U$-value of the envelope. The shading coefficient and $U$ value of each HISG are lower than those of the semitransparent PV modules. During summer, solar radiation cannot enter the room easily through the HISG, so cooling energy can be saved. During winter, the $U$-value of the HISG is very low, owing to the multilayer structure, and although solar radiation cannot enter the room easily, the heat will be retained inside the room and will not dissipate easily, and hence the amount of energy used for heating can also be reduced. Therefore, the simulation results for the HISGs all indicate greater energy-saving performance in the annual energy consumption of the HVAC system. The results show that the HISG can save 29.11-32.19\% of cooling energy, 47.34$48.15 \%$ of heating energy, and $32.68-35.75 \%$ of the total energy consumption of the HVAC system in subtropical regions and $37.27-44.12 \%$ of cooling energy, $39.05-39.86 \%$ of heating energy, and 39.05-39.86\% of total energy consumption of the HVAC system in temperate regions. Among all the HISGs, the HISG encapsulated version using heat insulation film $\mathrm{C}$ had the best energy-saving performance.

As seen in the simulation results given above, the HISG can not only enhance the power generation, but also, because of the better heat insulation performance, shorten the EPBT of the entire HISG BIPV application on a building.

\section{Conclusion}

The concepts of net zero energy, zero energy, and passive energy are becoming more important as part of the energy conservation policies adopted by the construction industry. BIPV technology currently has great potential for effective development of solar module techniques. Theoretically, if a BIPV module is combined with building materials, it can effectively reduce overall construction costs, save energy, modulate the indoor temperature, and shorten the energy payback time (EPBT).

In this work, the authors adopted three different types of semitransparent PV modules and combined three different types of high-reflectivity films to encapsulate HISG BIPV systems. The optical and thermal properties and the overall power generation effects of each HISG were investigated. In addition, Autodesk software was used to calculate the power generation and energy-saving effects of each HISG as applied to actual buildings in Taiwan, with a subtropical climate, and England, with a temperate climate. As a result, due to the three-layer structure of the HISG with a high-reflectivity heat insulation film, the heat insulation performance (SHGC and 


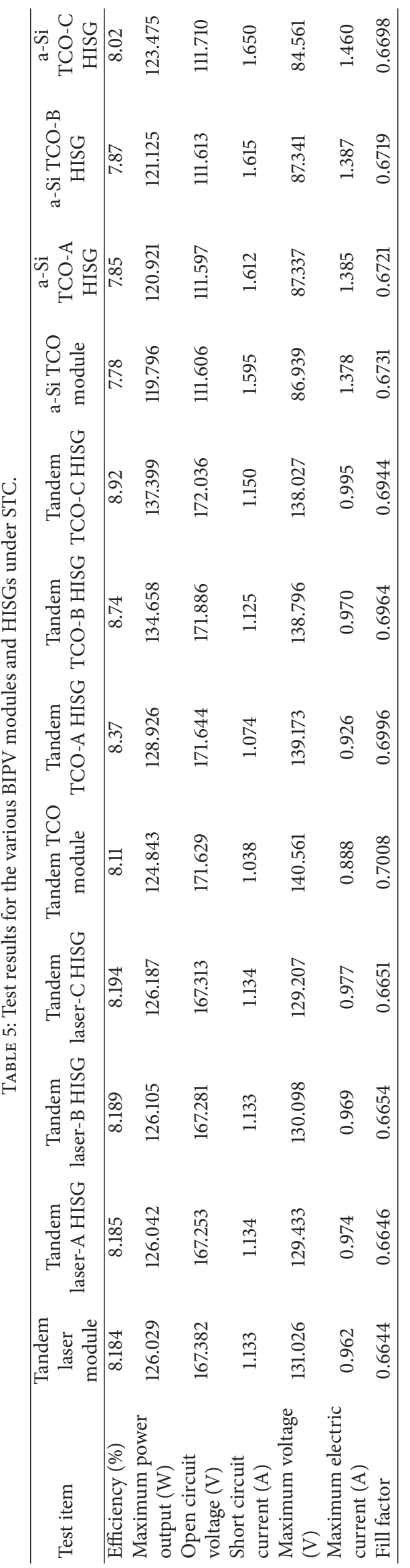


TABLE 6: Results of power generation gain tests of the semitransparent PV modules and each combination of HISG under STC.

\begin{tabular}{|c|c|c|c|c|}
\hline \multirow[b]{2}{*}{ Module } & \multicolumn{4}{|c|}{ Item } \\
\hline & Power generation (W) & $\begin{array}{l}\text { Power generation } \\
\text { enhancement }(\%)\end{array}$ & Module efficiency (\%) & $\begin{array}{l}\text { Module efficiency } \\
\text { enhancement (\%) }\end{array}$ \\
\hline Tandem laser module & 126.029 & - & 8.184 & - \\
\hline Tandem laser-A HISG & 126.042 & 0.01 & 8.185 & 0.001 \\
\hline Tandem laser-B HISG & 126.105 & 0.06 & 8.189 & 0.005 \\
\hline Tandem laser-C HISG & 126.187 & 0.13 & 8.194 & 0.010 \\
\hline Tandem TCO module & 124.843 & - & 8.11 & - \\
\hline Tandem TCO-A HISG & 128.926 & 3.27 & 8.37 & 0.27 \\
\hline Tandem TCO-B HISG & 134.658 & 7.86 & 8.74 & 0.64 \\
\hline Tandem TCO-C HISG & 137.399 & 10.06 & 8.92 & 0.82 \\
\hline a-Si TCO module & 119.796 & - & 7.78 & - \\
\hline a-Si TCO-A HISG & 120.921 & 0.94 & 7.85 & 0.07 \\
\hline a-Si TCO-B HISG & 121.125 & 1.11 & 7.87 & 0.09 \\
\hline a-Si TCO-C HISG & 123.475 & 3.07 & 8.02 & 0.24 \\
\hline
\end{tabular}

TABLE 7: Power generation results for building body simulations.

\begin{tabular}{lcccc}
\hline \multirow{2}{*}{ Module } & \multicolumn{4}{c}{ Location } \\
& Tainan, Taiwan $(\mathrm{kW})$ & Power enhancement (\%) & London, UK (kW) & Power enhancement (\%) \\
\hline Tandem laser module & 17178 & - & 8935 & - \\
Tandem laser-A HISG & 17179 & 0.01 & 8936 & 0.01 \\
Tandem laser-B HISG & 17188 & 0.06 & 8940 & 0.06 \\
Tandem laser-C HISG & 17199 & 0.12 & 8946 & 0.12 \\
\hline Tandem TCO module & 17016 & - & 8851 & - \\
Tandem TCO-A HISG & 17573 & 3.27 & 9141 & 3.27 \\
Tandem TCO-B HISG & 18354 & 7.86 & 9547 & 7.86 \\
Tandem TCO-C HISG & 18727 & 10.06 & 9741 & 10.06 \\
\hline a-Si TCO module & 16328 & - & 8493 & - \\
a-Si TCO-A HISG & 16481 & 0.94 & 8573 & 0.94 \\
a-Si TCO-B HISG & 16509 & 1.11 & 8587 & 8754 \\
a-Si TCO-C HISG & 16830 & 3.07 & & 3.11 \\
\hline
\end{tabular}

TABLE 8: Simulation results for energy consumption of HVAC systems for the building body in the Tainan region of Taiwan.

\begin{tabular}{|c|c|c|c|c|c|c|}
\hline Module & $\begin{array}{c}\text { Cooling energy } \\
\text { consumption (kW) }\end{array}$ & $\begin{array}{l}\text { Cooling energy } \\
\text { saving }(\%)\end{array}$ & $\begin{array}{c}\text { Heating energy } \\
\text { consumption } \\
(\mathrm{kW})\end{array}$ & $\begin{array}{l}\text { Heating energy } \\
\text { saving (\%) }\end{array}$ & $\begin{array}{c}\text { Total HVAC system } \\
\text { energy consumption } \\
(\mathrm{kW})\end{array}$ & $\begin{array}{c}\text { Total HVAC } \\
\text { energy saving } \\
(\%)\end{array}$ \\
\hline Tandem laser module & 28632 & - & 6924 & - & 35556 & - \\
\hline Tandem laser-A HISG & 20296 & 29.11 & 3639 & 47.44 & 23935 & 32.68 \\
\hline Tandem laser-B HISG & 20053 & 29.96 & 3590 & 48.15 & 23643 & 33.50 \\
\hline Tandem laser-C HISG & 19958 & 30.29 & 3591 & 48.14 & 23549 & 33.77 \\
\hline Tandem TCO module & 29495 & - & 6894 & - & 36390 & - \\
\hline Tandem TCO-A HISG & 20793 & 29.50 & 3623 & 47.45 & 24415 & 32.91 \\
\hline Tandem TCO-B HISG & 20412 & 30.80 & 3576 & 48.13 & 23988 & 34.08 \\
\hline Tandem TCO-C HISG & 20201 & 31.51 & 3583 & 48.03 & 23784 & 34.64 \\
\hline a-Si TCO module & 30368 & - & 6869 & - & 37236 & - \\
\hline a-Si TCO-A HISG & 20952 & 31.01 & 3617 & 47.34 & 24569 & 34.02 \\
\hline a-Si TCO-B HISG & 20593 & 32.19 & 3568 & 48.06 & 24161 & 35.11 \\
\hline a-Si TCO-C HISG & 20347 & 33.00 & 3577 & 47.93 & 23924 & 35.75 \\
\hline
\end{tabular}


TABLE 9: Simulation results for energy consumption of HVAC systems for the building body in London, UK.

\begin{tabular}{|c|c|c|c|c|c|c|}
\hline Module & $\begin{array}{c}\text { Cooling energy } \\
\text { consumption } \\
(\mathrm{kW})\end{array}$ & $\begin{array}{l}\text { Cooling energy } \\
\text { saving (\%) }\end{array}$ & $\begin{array}{c}\text { Heating energy } \\
\text { consumption } \\
(\mathrm{kW})\end{array}$ & $\begin{array}{l}\text { Heating energy } \\
\text { saving (\%) }\end{array}$ & $\begin{array}{l}\text { Total HVAC system energy } \\
\text { consumption }(\mathrm{kW})\end{array}$ & $\begin{array}{c}\text { Total HVAC } \\
\text { energy saving } \\
(\%)\end{array}$ \\
\hline Tandem laser module & 306 & - & 116818 & - & 117123 & - \\
\hline Tandem laser-A HISG & 181 & 40.85 & 71203 & 39.05 & 71384 & 39.05 \\
\hline Tandem laser-B HISG & 171 & 44.12 & 70570 & 39.59 & 70741 & 39.60 \\
\hline Tandem laser-C HISG & 173 & 43.46 & 70491 & 39.66 & 70664 & 39.67 \\
\hline Tandem TCO module & 271 & - & 117612 & - & 117883 & - \\
\hline Tandem TCO-A HISG & 170 & 37.27 & 71497 & 39.21 & 71667 & 39.20 \\
\hline Tandem TCO-B HISG & 164 & 39.48 & 70753 & 39.84 & 70917 & 39.84 \\
\hline Tandem TCO-C HISG & 165 & 39.11 & 70734 & 39.86 & 70899 & 39.86 \\
\hline a-Si TCO module & 287 & - & 117214 & - & 117501 & - \\
\hline a-Si TCO-A HISG & 175 & 39.02 & 71273 & 39.19 & 71448 & 39.19 \\
\hline a-Si TCO-B HISG & 172 & 40.07 & 70640 & 39.73 & 70812 & 39.73 \\
\hline a-Si TCO-C HISG & 171 & 40.42 & 70566 & 39.80 & 70737 & 39.80 \\
\hline
\end{tabular}

$U$-value) showed an improvement. Although the multilayer structure of HISG would affect the visible light transmittance, in practice, it does not have a significant impact on the view through the glass. Moreover, although the solar direct reflectance values all showed improving trends, the visible light reflectance was only around 5\%, which will not necessarily cause environmental light pollution. Compared to the original modules, the power generation and module efficiency of all HISGs were found to have increased. Of all the combinations of HISGs, the gain in power generation of the tandem TCO-C HISG was the highest, as the power generation was improved by $10.06 \%$ and the module efficiency was improved by $0.82 \%$. The results of the simulation showed a very similar trend with regard to the level of electrical power generation, based on experimental data that was obtained using the standard test conditions (STC) for measurement contained in IEC 61646. The simulation results also indicated that the HISG has a significant effect on the amount of energy that can be saved when using the HVAC system in both subtropical and temperate regions.

This paper thus provides valuable information for renewable energy planners and architectural designers who are interested in using HISG BIPV systems.

\section{Competing Interests}

The authors declare that there are no competing interests regarding the publication of this paper.

\section{Acknowledgments}

This study was supported by the Ministry of Science and Technology of Taiwan under Projects MOST 105-3113-F-011001 and MOST 105-3113-E-006-006-CC2.

\section{References}

[1] M. van der Hoeven, Energy and Climate Change-World Energy Outlook Special Report, International Energy Agency, 2015.
[2] P. Jones, S. S. Hou, and X. Li, “Towards zero carbon design in offices: integrating smart facades, ventilation, and surface heating and cooling," Renewable Energy, vol. 73, pp. 69-76, 2015.

[3] W. Pan, "System boundaries of zero carbon buildings," Renewable and Sustainable Energy Reviews, vol. 37, pp. 424-434, 2014.

[4] S. Berry, K. Davidson, and W. Saman, "Defining zero carbon and zero energy homes from a performance-based regulatory perspective," Energy Efficiency, vol. 7, no. 2, pp. 303-322, 2014.

[5] G. P. Hammond, H. A. Harajli, C. I. Jones, and A. B. Winnett, "Whole systems appraisal of a UK Building Integrated Photovoltaic (BIPV) system: energy, environmental, and economic evaluations," Energy Policy, vol. 40, no. 1, pp. 219-230, 2012.

[6] G. A. Keoleian and G. M. Lewis, "Modeling the life cycle energy and environmental performance of amorphous silicon BIPV roofing in the US," Renewable Energy, vol. 28, no. 2, pp. 271-293, 2003.

[7] L. Lu and H. X. Yang, "Environmental payback time analysis of a roof-mounted building-integrated photovoltaic (BIPV) system in Hong Kong," Applied Energy, vol. 87, no. 12, pp. 3625-3631, 2010.

[8] L. Y. Seng, G. Lalchand, and G. M. Sow Lin, "Economical, environmental and technical analysis of building integrated photovoltaic systems in Malaysia," Energy Policy, vol. 36, no. 6, pp. 2130-2142, 2008.

[9] M. Oliver and T. Jackson, "Energy and economic evaluation of building-integrated photovoltaics," Energy, vol. 26, no. 4, pp. 431-439, 2001.

[10] L. Sabnani, A. Skumanich, E. Ryabova, and R. Noufi, Developing Market Opportunities for Flexible Rooftop Applications of PV Using Flexible CIGS Technology: Market Considerations, National Renewable Energy Laboratory (NREL), Golden, Colo, USA, 2011

[11] M. A. Green, K. Emery, Y. Hishikawa, W. Warta, and E. D. Dunlop, "Solar cell efficiency tables (version 47)," Progress in Photovoltaics: Research and Applications, vol. 24, no. 1, pp. 3-11, 2016.

[12] G. Y. Yun, M. McEvoy, and K. Steemers, "Design and overall energy performance of a ventilated photovoltaic façade," Solar Energy, vol. 81, no. 3, pp. 383-394, 2007. 
[13] P. W. Wong, Y. Shimoda, M. Nonaka, M. Inoue, and M. Mizuno, "Semi-transparent PV: thermal performance, power generation, daylight modelling and energy saving potential in a residential application," Renewable Energy, vol. 33, no. 5, pp. 1024-1036, 2008.

[14] D. H. W. Li, T. N. T. Lam, W. W. H. Chan, and A. H. L. Mak, "Energy and cost analysis of semi-transparent photovoltaic in office buildings," Applied Energy, vol. 86, no. 5, pp. 722-729, 2009.

[15] H. Radhi, "Energy analysis of façade-integrated photovoltaic systems applied to UAE commercial buildings," Solar Energy, vol. 84, no. 12, pp. 2009-2021, 2010.

[16] E. L. Didoné and A. Wagner, "Semi-transparent PV windows: a study for office buildings in Brazil," Energy and Buildings, vol. 67, pp. 136-142, 2013.

[17] P. K. Ng and N. Mithraratne, "Lifetime performance of semitransparent building-integrated photovoltaic (BIPV) glazing systems in the tropics," Renewable and Sustainable Energy Reviews, vol. 31, pp. 736-745, 2014.

[18] C. H. Young, Y. L. Chen, and P. C. Chen, "Heat insulation solar glass and application on energy efficiency buildings," Energy and Buildings, vol. 78, pp. 66-78, 2014.

[19] International Organization for Standardization, ISO 9050: Glass in Building-Determination of Light Transmittance, Solar Direct Transmittance, Total Solar Energy Transmittance, Ultraviolet Transmittance and Related Glazing Factors, International Organization for Standardization, Basel, Switzerland, 2003.

[20] International Organization for Standardization, "ISO10292: glass in building - calculation of steady-state U values (thermal transmittance) of multiple glazing," Tech. Rep., International Organization for Standardization, Geneva, Switzerland, 1994.

[21] International Standard, "Thin-film terrestrial photovoltaic (pv) modules-design qualification and type approval," IEC 61646, 2008. 

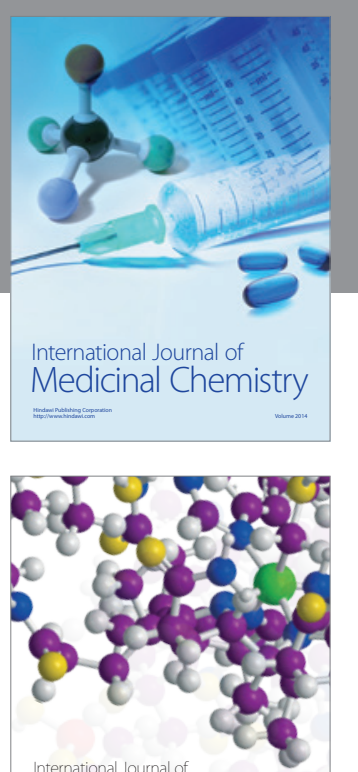

Carbohydrate Chemistry

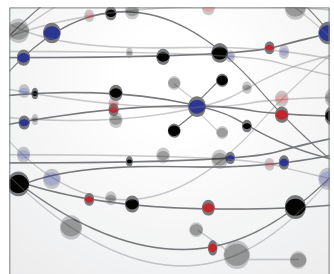

The Scientific World Journal
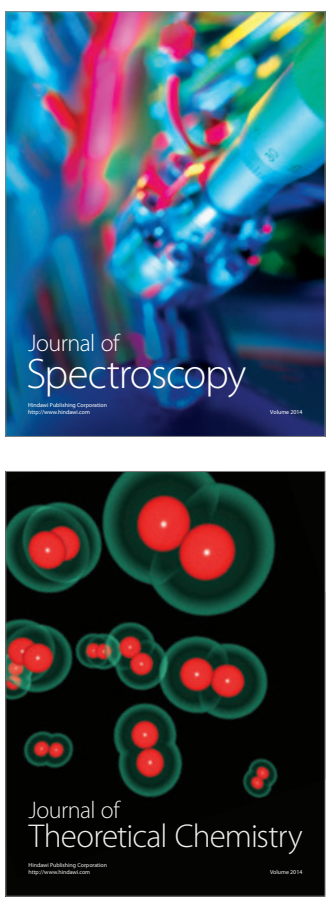
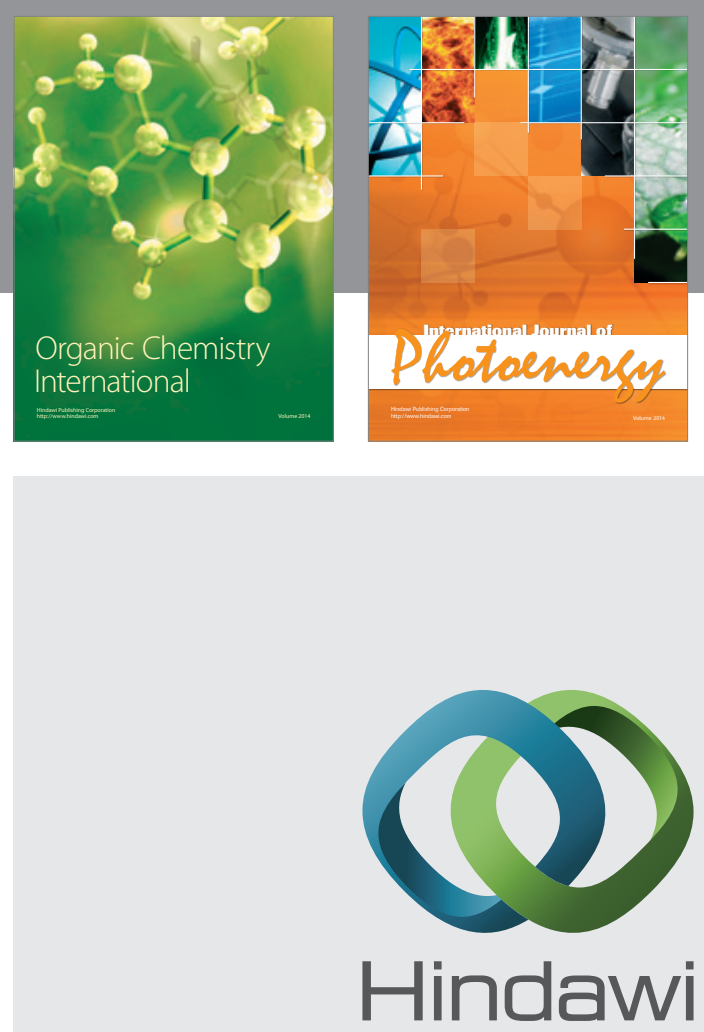

Submit your manuscripts at

http://www.hindawi.com

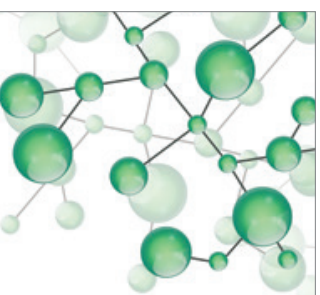

International Journal of

Inorganic Chemistry

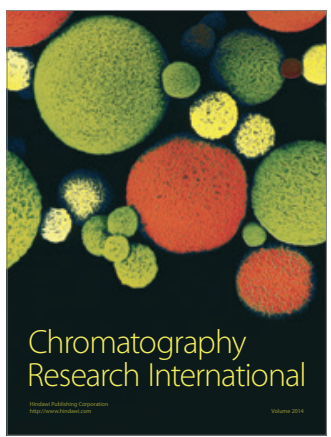

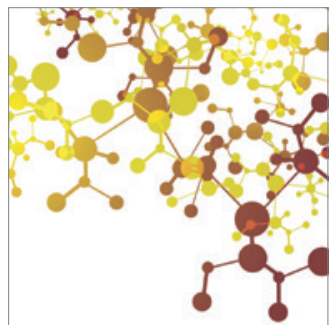

Applied Chemistry
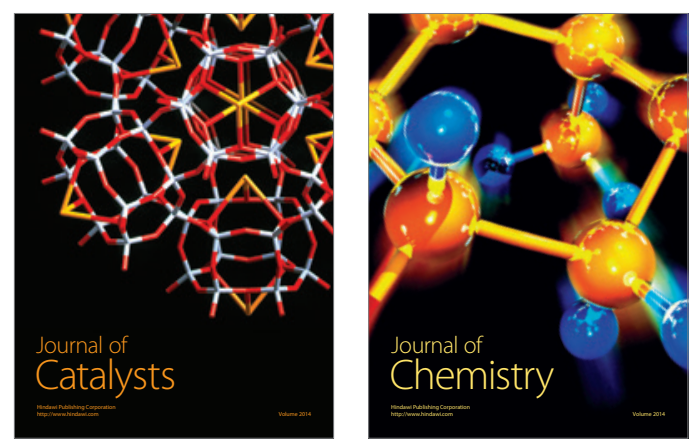
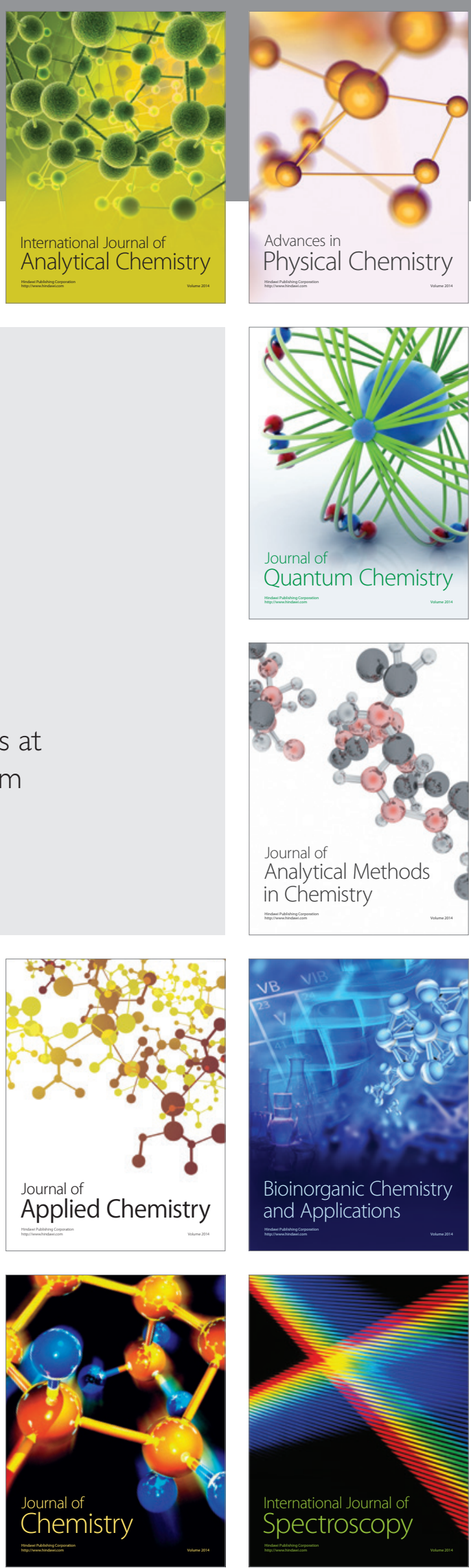